\title{
Most popular article awards
}

\section{Geoff Norman}

(C) Springer Science+Business Media B.V. 2011

As a result of a decision by the Editorial Board, we will be awarding annual prizes for the most downloads of a review article and an original study. Winners will be chosen by a sum of downloads for each calendar year, and need not have been published in AHSE in the calendar year.

This year's winners are both related to Reflective Practice. Karen Mann, Jill Gordon and Anna MacLeod of Dalhousie University, Canada, University of Sydney, Australia and University of South Australia, won the review article award for their systematic review "Reflection and reflective practice in health professions: A systematic review (AHSE 14:4, pp. 595-621)". This was a broad and comprehensive synthesis of 29 original articles of reflection in health professions. Clare Delaney and Deborah Watkin, of the University of Melbourne, won the original study prize for a qualitative study of reflection skills following a course for third year physiotherapy students, "A study of critical reflection in health professional education: 'learning where others are coming from"” (AHSE 14.3, pp. 411-429).

Congratulations to both groups. They will receive a formal letter and a plaque honouring their achievements. 